\title{
Co-Detoxification of Transformer Oil-Contained PCBs and Heavy Metals in Medical Waste Incinerator Fly Ash under Sub- and Supercritical Water
}

Chunfeng Wang, ${ }^{\dagger \dagger}$ Nengmin Zhu, ${ }^{\dagger}$ Yanmin Wang, ${ }^{\dagger}$ and Fushen Zhang ${ }^{*}{ }^{\dagger}$

${ }^{\dagger}$ Research Center for Eco-Environmental Sciences, Chinese Academy of Sciences, 18 Shuangqing Road, Beijing 100085, People’s Republic of China

\section{Supporting Information}

ABSTRACT: The simultaneous detoxification processes of transformer oil-contained PCBs and heavy metals in medical waste incinerator (MWI) fly ash were developed under sub- and supercritical water. The addition of MWI fly ash to transformer oil-contained PCBs was found to increase the destruction efficiency of PCBs, at the same time, it facilitated reducing the leaching concentration of toxic metals from residues (obtained after reaction) for harmless disposal. In this study, we elucidated primarily the catalysis possibility of heavy metals in raw MWI fly ash for PCBs degradation by adopting the sequential extraction procedure. For both MWI fly ashes, more than $90 \%$ destruction efficiency of PCBs was achieved at $\geq 375{ }^{\circ} \mathrm{C}$ for $30 \mathrm{~min}$, and trichlorobenzene (TCB) existing in the transformer oil was also completely decomposed. The correlation of catalytic performance to PCBs degradation was discussed based on structural characteristics and dechlorinated products. Likewise, such process rendered residues innocuous through supercritical water treatment for reuse or disposal in landfill.

\section{INTRODUCTION}

Polychlorinated biphenyls (PCBs) are typical persistent organic pollutant (POPs), which are listed in the Stockholm Convention as priority pollutants for ultimate elimination. The actual and potential release of PCBs in waste dielectric oils causes serious cross-contamination for the environment and human health because these compounds still remain in large quantities in, e.g., capacitors, electrical transformers, or storage, which remains a scientific and technical challenge. Alternative technologies have been employed to treat polyhalogenated aromatics including bioremediation, ${ }^{1}$ electrocatalytic hydrodechlorination, $^{2-4}$ irradiation, $^{5,6}$ and catalytic degradation ${ }^{7-10}$ during the last two decades. Among a variety of promising approaches, catalytic sub- and supercritical water techniques have received considerable attention for treatment of polychlorinated and other halogenated contaminants via an oxidation $^{11,12}$ or reductive process. ${ }^{13-15}$ In previous studies, the most common ways of reductive dehalogenation are the methods based on subcritical water with the addition of zerovalent metals paticles which are extremely chemically reactive. Kubátová et al. ${ }^{13}$ performed the dechlorination of PCBs (Aroclor 1254) on several zerovalent metals in subcritical water, and proved that the ability of zerovalent and divalent lead to dechlorination was higher than that of other zerovalent metals $(\mathrm{Cu}, \mathrm{Al}, \mathrm{Zn}$, and $\mathrm{Fe})$ under the same conditions. Later, Hori et al. ${ }^{14}$ investigated decomposition of perfluorooctanesulfonate (PFOS) in subcritical water with the addition of each zerovalent metal $(\mathrm{Cu}, \mathrm{Al}, \mathrm{Zn}$, and $\mathrm{Fe})$ and found that zerovalent iron showed the best activity among these selected catalysts. Meanwhile, the use of bimetallic systems (nanosized $\mathrm{Fe} / \mathrm{Ni}$ particles) has been documented by Zhu et al. ${ }^{16}$ to work efficiently for reductive dechlorination of PCBs (Aroclor 1242) in subcritical water. However, they are not adapted to largescale applications owing to their high cost and rapid deactivation, especially in the utilization of several noble metals.

Medical waste incinerator (MWI) fly ash is classified as "hazardous waste" as the heavy metals concentration of Toxicity Characteristic Leaching Procedure (TCLP) exceeded regulations. Sub- and supercritical water extraction of heavy metals from MWI fly ash has attracted more research attention due to its technological and economical advantages over the conventional methods such as cementation and vitrification. ${ }^{17,18}$ Moreover, highly stable organic pollutants (PAHs and dioxin) existing in MWI fly ash can also be degraded effectively during the process of sub- and supercritical water. ${ }^{19}$ It is noticed that the catalytic activity of transition metals, including $\mathrm{Cu}-, \mathrm{Pb}-$, and $\mathrm{Zn}$-bearing MWI fly ash is of great concern. Nothing in the literature is reported on their catalytic properties for PCBs dechlorination under sub- and supercritical water.

\section{Received: July 7, 2011}

Revised: October 29, 2011

Accepted: December 5, 2011

Published: December 5, 2011 
Consequently, the main goal of this study was to investigate a simultaneous treatment process based on catalytic degradation of transformer oil-contained PCBs by transition metals $(\mathrm{Cu}, \mathrm{Pb}$, and $\mathrm{Zn}$ ) bearing MWI fly ash along reduction of leachability of toxic metals from MWI fly ash under sub- and supercritical water. Transition metals bound to exchangeable and carbonate fractions play an important role in PCBs degradation. Thus, the information on the distribution patterns of transition metals bearing both MWI fly ashes was first obtained by using sequential extraction procedure, which contributed to evaluate their catalytic feasibility in reaction system. And then, investigation of PCBs degradation on MWI fly ash may provide further insight into the mechanism and the feasibility of reductive dechlorination. Waste transformer oil-contained PCBs was chosen for performing dechlorination due to its complicated composition of various highly chlorinated PCBs congeners. In parallel, the leachability of toxic metals from treated MWI fly ash (residues) was determined by a series of TCLP tests for evaluating environment impacts.

\section{EXPERIMENTAL SECTION}

Materials and Chemicals. For our work, a representative sample of transformer oil-contained PCBs was obtained from a certified Chinese company that is in charge of the incineration treatment of all waste dielectric oils throughout the country. The used high-level transformer oil closely matched the congener patterns of Aroclor 1260 by means of GC/MS chromatographic analysis (Figure 1), which is typical of

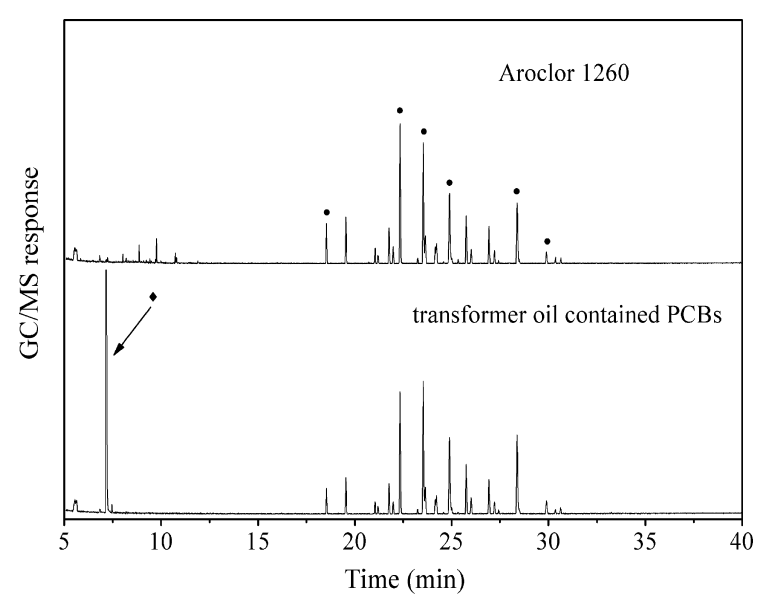

Figure 1. Comparison of GC/MS chromatograms of Aroclor 1260 and transformer oil-contained PCBs six major congeners of Aroclor 1260; trichlorobenzene).

transformer oil, ${ }^{20}$ and the composition of it contains Aroclor 1260 and trichlorobenzene (consisting of main 1,3,5-TCB and other trace isomer), corresponding to concentrations of about 700000 and $650000 \mu \mathrm{g} \mathrm{g}^{-1}$.

Stock solution of the transformer oil was prepared by dissolution in hexane which contained Aroclor 1260 and TCB at concentrations of $67 \pm 5$ and $64 \pm 3 \mathrm{mg} \mathrm{L}^{-1}$, respectively. Both types of fly ashes were produced from the large-scale medical waste incinerator during the outbreak of SARS (Severe Acute Respiratory Syndrome) in Taiwan and Beijing, and were denoted as MFA1 and MFA2. MWI fly ashes were dried at 40 ${ }^{\circ} \mathrm{C}$ for $48 \mathrm{~h}$ to avoid PAHs losses. ${ }^{21}$ The method for the extraction, cleanup, and analysis of PAHs concentration (16 USEPA priority) in MWI fly ashes is described in detail in the
Supporting Information (SI) Text S1 and the results are displayed in SI Table S1. The metals composition of MWI fly ashes was determined by inductively coupled plasma-optical emission spectrometry (ICP-OES, PerkinElmer) after digestion and is listed in SI Table S2. The crystalline phases of MWI fly ashes and residues obtained after reaction were examined by a Phillips PW 170 X-ray diffractometer (SI Figure S1), and the surface morphology of MWI fly ashes was examined by a scanning electron microscope (SEM, Hitach S-3000N) (SI Figure S2).

Batch Experiments. All experiments were performed using a static $100-\mathrm{mL}$ autoclave constructed from 316 stainless steel. To test the catalytic effect of both MWI fly ashes, $3 \mathrm{~mL}$ of stock solution was spiked directly into the autoclave containing 1,2 , and $3 \mathrm{~g}$ of fly ash samples. The hexane was allowed to airdry under prepurified nitrogen at ambient temperature, and 55 $\mathrm{mL}$ of deionized water previously purged with nitrogen was placed in the autoclave. The autoclave was sealed and placed into a cylindrical electric furnace for heating. After flushing with pure argon, the autoclave was heated with a rate of ca. $10{ }^{\circ} \mathrm{C}$ $\mathrm{min}^{-1}$ to the respective temperature for the chosen reaction time. The temperature in the autoclave was measured through an internally installed thermocouple covered by Hastelloy C276 to resist the harsh reaction conditions. The internal autoclave pressure was governed autogenously along with the temperature change and read with a pressure sensor. Thus, pressures were ca. $7.0,14.2,23.5,28.1$, and $34.4 \mathrm{MPa}$ for reactions performed at $280,330,375,390$, and $410{ }^{\circ} \mathrm{C}$, respectively. The reaction was finally quenched by water spray for rapid cooling. After opening each autoclave, the surrogate standard decachlorobenzene (PCB 209) was added. Comparatively, we performed the degradation experiments of $3 \mathrm{~mL}$ of stock solution under sub- and supercritical pure water (55 $\mathrm{mL})$.

Each experiment was performed in triplicate and the mean value was used in this study. The reproducibility of the results was below $\pm 10 \%$ variability.

Extraction, Cleanup, and Analysis. The reaction mixture was centrifuged to separate the aqueous phase and the solid phase (residues). The solid residues were dried in air overnight and extracted using Soxhlet method with $100 \mathrm{~mL}$ of solvent mixture of hexane/acetone $(1: 1, \mathrm{v} / \mathrm{v})$ for $24 \mathrm{~h}$. The aqueous phase was subjected to sequential liquid-liquid extraction with $50 \mathrm{~mL}$ of dichloromethane for $24 \mathrm{~h}$. Also, the autoclave was washed three times, each with ca. $5 \mathrm{~mL}$ of acetone (in an effort to remove the sample substance). All three collected portions were preconcentrated with rotary evaporation to a volume of ca. $2 \mathrm{~mL}$, which was maintained to gently nitrogen-sparge to ca. $1 \mathrm{~mL}$ with solvent-exchange of hexane. Sample cleanup passed through a multilayer column which contained anhydrous sodium sulfate, silical gel, and alumina column using $80 \mathrm{~mL}$ of hexane/dichloromethane $(1: 1, \mathrm{v} / \mathrm{v})$ elution. Finally, $1 \mathrm{~mL}$ of water-free sample was transferred to a $1.5 \mathrm{~mL}$ autosample vial with a Teflon-coated stopper and spiked with $10 \mu \mathrm{L}$ of the internal standard, hexachlorobenzene, for analysis in a gas chromatograph (GC, Agilent 7890A)/mass spectrometer (MS, Agilent $5975 \mathrm{C}$ ) equipped with a HP-5 $30 \mathrm{~m} \times 0.25 \mathrm{~mm} \times 0.25$ $\mu \mathrm{m}$ capillary column using splitless injections. Two types of quantitation were performed: (1) destruction efficiency of PCBs was determined using "total Aroclor 1260" concentrations based on the calibration with Aroclor 1260 using six major congeners (EPA method 8082A); (2) individual congener concentrations based on the peak area of the internal 
standard. The work of Frame et al. ${ }^{22}$ was used as a reference for composition of the Aroclors. Moreover, the concentration of biphenyl existing in each sample was quantified by five-point calibration curves using the standard individual component in hexane.

Leaching Experiments for Heavy Metals. TCLP analysis was employed on the leachability of hazardous heavy metals from raw MWI fly ashes and the solid residues for evaluating the feasibility of their reuse or disposal in landfill, in which two kinds of extraction solutions were used (EPA method 1311). All TCLP experiments were performed in a batch stoppered conical flask $(50 \mathrm{~mL})$ according to liquid-tosolid ration $(20: 1, \mathrm{~mL} / \mathrm{g})$, and agitation time was $18 \pm 2 \mathrm{~h}$ at a $30 \mathrm{rpm}$ constant shaking rate. After extraction, the leachates were filtered through a glass fiber filter paper of $0.45-\mu \mathrm{m}$ pore size and acidified with $3 \% \mathrm{HNO}_{3}$ (wt \%) before being analyzed by ICP-OES.

\section{RESULTS AND DISCUSSION}

Heavy Metals Fractions in Both MWI Fly Ashes. The five fractions distribution of various metals in both raw MWI fly ashes was evaluated by the sequential extraction procedure (SI Text S2) suggested by Tesseir et al. (Figure 2). ${ }^{23}$

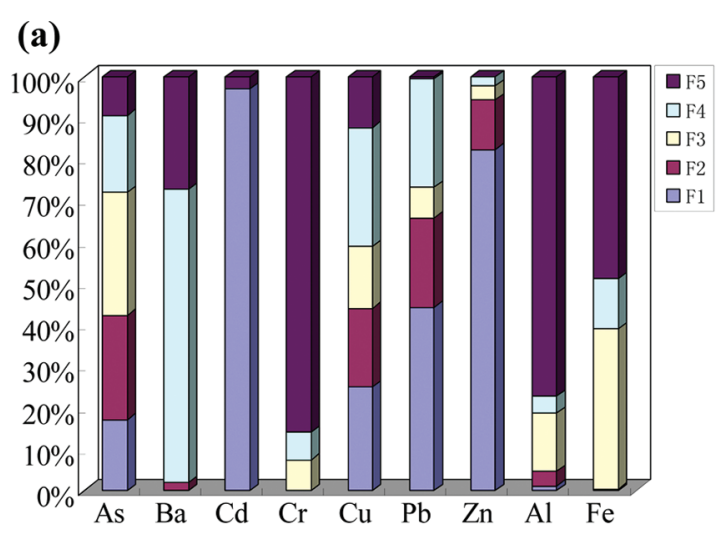

(b)

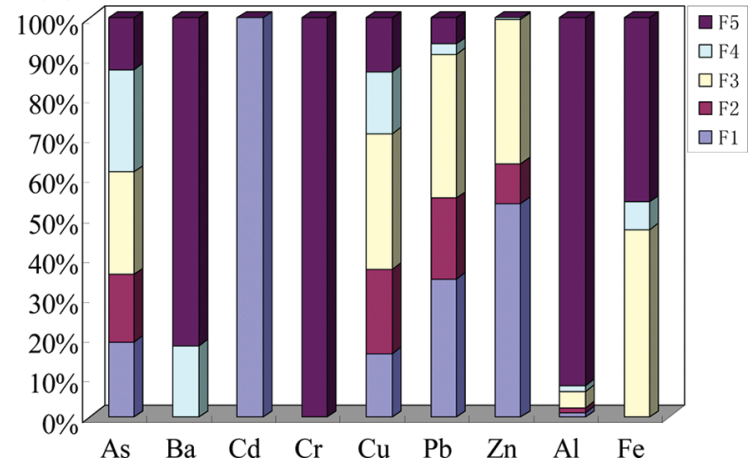

Figure 2. Metals distribution patterns of (a) MFA1, (b) MFA2 (F1: exchangeable; F2: carbonate; F3: Fe-Mn oxide; F4: organic matter; F5: residual fraction)

With exception of $\mathrm{Ba}, \mathrm{Cr}, \mathrm{Al}$, and $\mathrm{Fe}$, most toxic elements, including $\mathrm{Cd}, \mathrm{Zn}, \mathrm{Pb}, \mathrm{Cu}$, and As, accumulated in exchangeable and carbonate fraction (mobile fractions) and the percentage of two fractions of these elements in both raw fly ashes followed the similar sequence: $\mathrm{Cd}>\mathrm{Zn}>\mathrm{Pb}>\mathrm{Cu}>$ As. The percentage of exchangeable fraction associated with $\mathrm{Cd}$ was the highest, accounting for $97.01 \%$ and $100 \%$, respectively, and the corresponding concentrations were 617 and $515.4 \mathrm{mg} \mathrm{kg}^{-1}$ for MFA1 and MFA2. Several toxic elements, such as Cd, Zn, $\mathrm{Pb}$, and As, with lower boiling points, could easily volatilize into flue gas during the incineration process, and thus condense on the surface of MWI fly ash particles by means of nucleation and deposition. ${ }^{24}$ Most of them could not entirely enter the lattice of particles in the form of metallic or metal oxides because the condensation reaction happened very fast, ${ }^{25}$ which indicated that these elements pose a risk of great leaching potential into the environment. Moreover, it is difficult to solidify such $\mathrm{NaCl}-$ rich MWI fly ash (SI Figure S1) since inorganic salts can hinder the hydration of cement, ${ }^{26}$ which can also cause slow release of heavy metals from the solidified products toward the environment. It should be noted that $\mathrm{Cu}$ species were never in the concentrated organic fraction due to its high concentrations on MWI fly ash (SI Table S2), which is inconsistent with the results reported by previous studies. ${ }^{27,28}$ Although $\mathrm{Al}$ and $\mathrm{Fe}$ attribute to innocuous metal, their patterns presented in $\mathrm{Fe}-\mathrm{Mn}$ oxide and organic matter may exert catalytic effect for PCBs degradation under sub- and supercritical water. It has been reported that metals bound to $\mathrm{Fe}-$ Mn oxide could not be immediately chemical reactive, but their mobility and availability could be potentially affected by the change of environmental conditions. ${ }^{29}$ Because the $\mathrm{pH}$ values of MFA1 and MFA2 are 3.56 and 5.84, respectively, transition metals could enter into the reaction system via structure decomposition of $\mathrm{Fe}-\mathrm{Mn}$ oxide under acidic circumstance and act as the favorable catalysis.

As stated previously, the higher amount of transition metals presented in both MWI fly ashes partly belong to mobile fractions, the potential availability of which would be desirable for PCBs degradation under sub- and supercritical water.

PCBs Destruction on Both MWI Fly Ashes. The destruction efficiency of PCBs on both MWI fly ashes was evaluated under sub- and supercritical water (Figure 3 ).

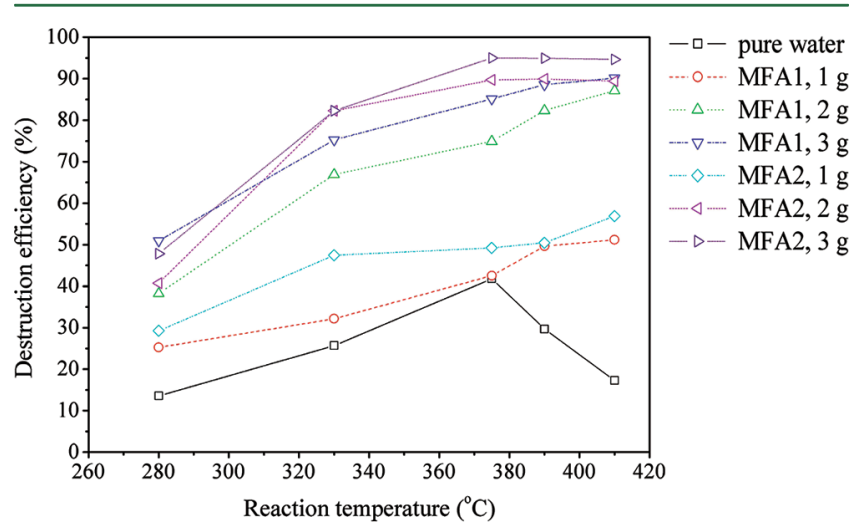

Figure 3. Destruction efficiency of transformer oil-contained PCBs (Aroclor 1260) on both MWI fly ashes and pure water in sub- and supercritical condition for $30 \mathrm{~min}$ (quantified as Aroclor 1260 (EPA method 8082A)).

As can be seen, the destruction efficiency of PCBs increased with a rise of MWI fly ash dosage. MFA1 and MFA2 have the highest destruction efficiency accounting for 90.13 and $94.99 \mathrm{wt}$ $\%$ at 410 and $375{ }^{\circ} \mathrm{C}$ over $3 \mathrm{~g}$, respectively. Enhanced destruction efficiency with higher MWI fly ashes loading is expected because the total available catalytic metals increase. Apparently, MFA2 showed higher destruction efficiency than MFA1. Another variable influencing destruction is reaction 
temperature. Figure 3 shows that a gradual increase in PCBs degradation was observed as reaction temperature increased from 280 to $410{ }^{\circ} \mathrm{C}$. However, destruction efficiency of PCBs on MFA2 slowed at both 2 and $3 \mathrm{~g}$ when reaction temperature was beyond $375{ }^{\circ} \mathrm{C}$. It should be noted that, for pure water, the decrease in destruction efficiency of PCBs was more pronounced when the reaction temperature increased from 375 to $410{ }^{\circ} \mathrm{C}$. This was a strong indication that a huge amount of the continuous generated byproduct, e.g., low chlorinated PCBs, could swiftly dominate degradation behavior and PCBs (Aroclor 1260) degradation was greatly restrained as a result in presence of the limited hydrogen sources (without catalysts) during the longer temperature-rise period (from room temperature to 375 and $410{ }^{\circ} \mathrm{C}$ ).

Calculation of the PCBs concentrations based on the total Aroclor (Figure 3) ignores the fact that some PCBs are dechlorinated to form lower chlorinated congeners, as displayed in Figure 4 by GC/MS chromatograms of the reaction products.

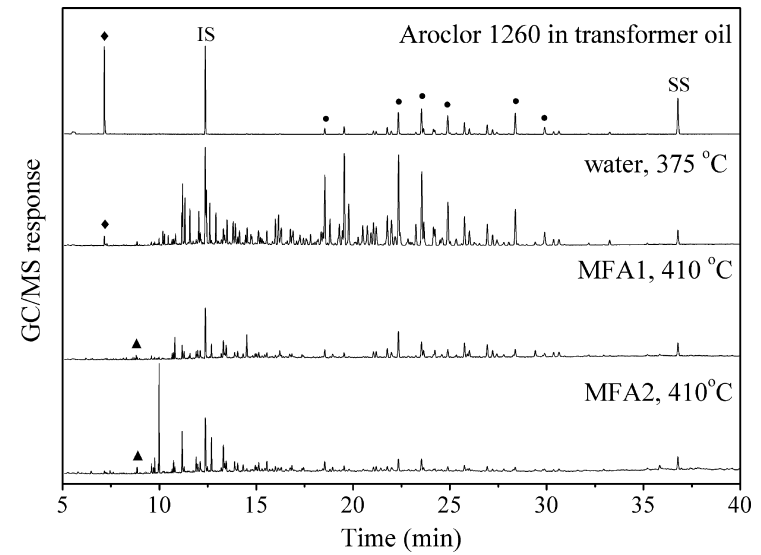

Figure 4. GC/MS chromatograms (same scale, $x$ (time) and $y$ (GC/ MS response), except for Aroclor 1260 in transformer oil) of transformer oil-contained PCBs before and after degradation on both MWI fly ashes $(3 \mathrm{~g})$ and pure water $(55 \mathrm{~mL})$ in supercritical condition for 30 min ( $\mathbf{A}$ biphenyl; six major congeners of Aroclor 1260; trichlorobenzene).

It is expected that sequential distribution of mono- to octachlorinated biphenyls in GC/MS chromatograms (Figure 4) showed that the original Aroclor 1260 partially dechlorinated in the presence of both MWI fly ashes at least, at the same time, biphenyl was also observed as reaction product in comparison to in pure water condition. It is important to note that a small amount of $\mathrm{TCB}$ in reaction product still remained after supercritical pure water treatment at $375^{\circ} \mathrm{C}$, whereas the use of MWI fly ashes can cause TCB to decompose completely.

Simple comparison based on the quantification of homologic groups also showed significant enhancement of PCBs degradation on both MWI fly ashes compared to that on pure water (Figure 5).

Only slight degradation was observed when performing the experiment with PCBs under supercritical pure water. In contrast, 90.13 and 94.63 wt \% PCBs destruction (as total Aroclor) was achieved for MFA1 and MFA2 at $410{ }^{\circ} \mathrm{C}$, respectively. This clearly demonstrated that a significant interaction between PCBs degradation and MWI fly ash under sub- and supercritical water. Generally, activated carbon was injected to air pollution control devices (APCD) to adsorb

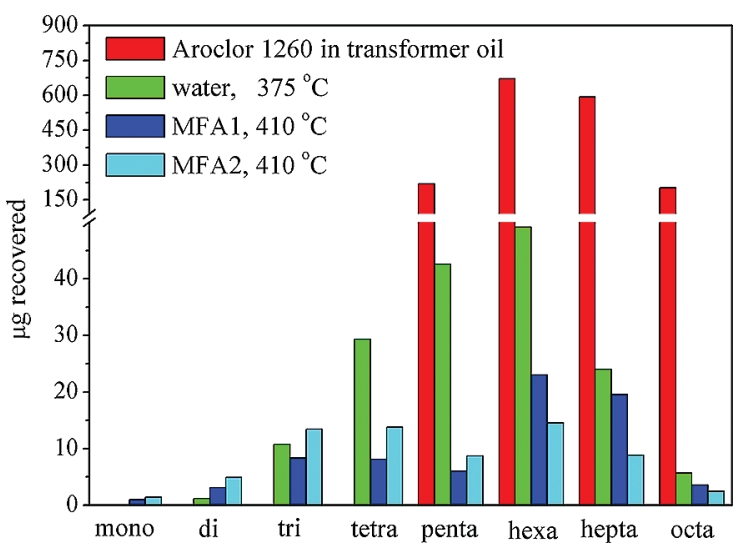

Figure 5. Homologue dependency of transformer oil-contained PCBs before and after degradation on both MWI fly ashes ( $3 \mathrm{~g})$ and pure water $(55 \mathrm{~mL})$ in supercritical condition for $30 \mathrm{~min}$.

effluent gases, which consist of heavy metals volatiles, organic compounds, and acidic gas, in the incineration facilities. As can be seen in SI Figure S2, MWI raw fly ash with loose structure was highly porous and provided a high surface area, which contributed to capturing pollutant molecules toward active sites. Under sub- and supercritical water, transition metals $(\mathrm{Cu}$, $\mathrm{Pb}$, and $\mathrm{Zn}$ ) cations in MWI fly ash (bound to exchangeable, carbonate, $\mathrm{Fe}-\mathrm{Mn}$ oxide, and organic matter) release into the reaction system under acidic condition, and these cations were not stable under carbon oxidation conditions owing to the reduction of these cations to zerovalent metals. The hydrogen produced from zerovalent metals $(\mathrm{Pb}$ and $\mathrm{Zn})$ corrosion would then attack the $\mathrm{PCBs}$ molecules via electrophilic $\mathrm{H}$ addition to the double bond of the benzene ring, followed by the $\mathrm{C}-\mathrm{Cl}$ scission. The schematic illustration of this process is shown below:

$$
\mathrm{M}(0)+\mathrm{ArCl}+\mathrm{H}^{+} \rightarrow \mathrm{ArH}+\mathrm{M}(\mathrm{II})+\mathrm{Cl}^{-}
$$

where $\mathrm{M}$ is indicative of zerovalent $\mathrm{Pb}$ or $\mathrm{Zn}$.

Ullmann reactions dominate the hydrodechlorination reactions for $\mathrm{Cu}$. Ullmann reactions can be described schematically as follows:

$$
\begin{aligned}
& \mathrm{ArCl}+\mathrm{Cu}(0) \rightarrow \operatorname{ArCu}(\mathrm{II}) \mathrm{Cl} \\
& \mathrm{ArCu}(\mathrm{II}) \mathrm{Cl}+\mathrm{ArCl} \rightarrow \mathrm{Ar}-\mathrm{Ar}+\mathrm{Cu}(\mathrm{II}) \mathrm{Cl}_{2}
\end{aligned}
$$

Lewin and Cohen ${ }^{30}$ summarized that Ullmann reactions were blocked by proton sources, which favor the dehalogenation of unstable organocopper intermediates compared to the formation of biaryls. Thus, the following reaction can also be considered responsible for PCBs dechlorination on MWI fly ash:

$$
\mathrm{ArCu}(\mathrm{II}) \mathrm{Cl}+\mathrm{H}^{+} \rightarrow \mathrm{ArH}+\mathrm{Cu}(\mathrm{II}) \mathrm{Cl}^{-}
$$

Concerning the catalytic effect of MWI fly ash, the mechanism illustrated by eqs 1-4 could contribute a lot to the improvement of PCBs degradation.

Figure 6 shows biphenyl yield of PCBs degradation with MWI fly ash loaded dosage under sub- and supercritical water for $30 \mathrm{~min}$.

Biphenyl could never be observed on the condition of pure water and $1 \mathrm{~g}$ of MWI fly ashes. When increasing MWI fly ash loaded dosage and reaction temperature, biphenyl yield in this study gradually increased. This phenomenon raised a 


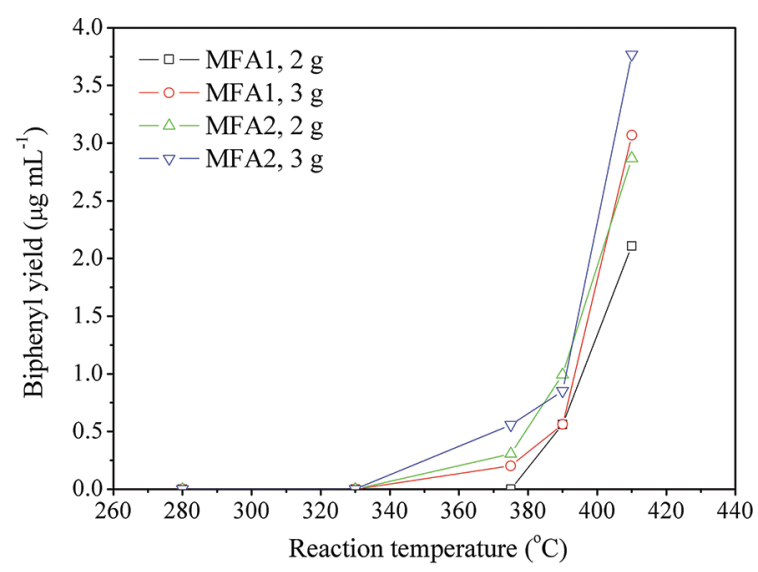

Figure 6. Biphenyl yield obtained from transformer oil-contained PCBs degradation on both MWI fly ashes under sub- and supercritical water for $30 \mathrm{~min}$.

remarkable concern that biphenyl was finally formed as main dechlorination product when higher chlorinated (penta-, hexa, hepta-, and octachlorinated) biphenyls were sequentially dechlorinated to lower chlorinated species in transformer oil.

Degradation Products and Pathway. The degradation products were further investigated by conducting PCBs degradation on $2 \mathrm{~g}$ of MFA2 in the range of $280-410{ }^{\circ} \mathrm{C}$ under sub- and supercritical water for $30 \mathrm{~min}$ (Figure 7), which

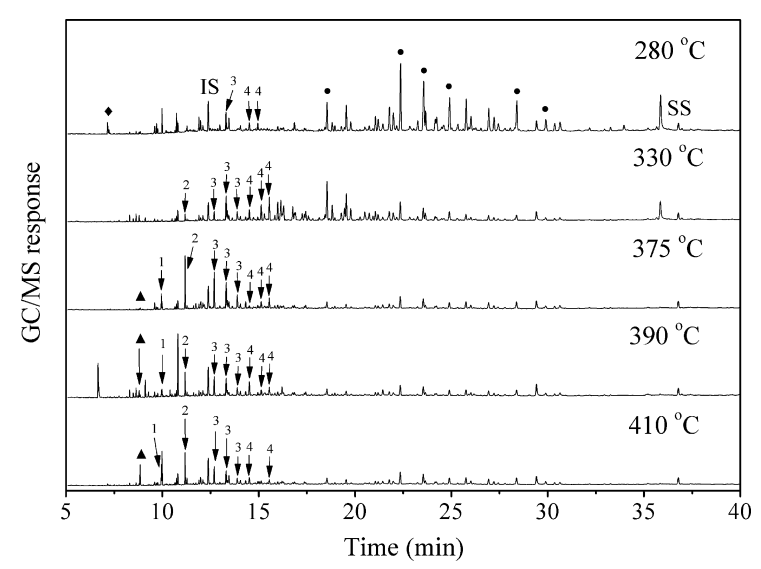

Figure 7. GC/MS chromatograms (same scale, $x$ (time) and $y$ (GC/ MS response), for all) of transformer oil-contained PCBs degradation on MFA2 (2 g) under sub- and supercritical water for $30 \mathrm{~min}(\boldsymbol{\Lambda}$ biphenyl; six major congeners of Aroclor 1260; zene). Peaks 1-4 of partly lower chlorinatedbiphenyls individually represent mono-, di-, tri-, and tetrachlorobiphenyls.

illustrated the same attenuation factor on the integrator (six major congeners). Moreover, there are only a limited number of TCB available at $280{ }^{\circ} \mathrm{C}$, accounting for $1.12 \mathrm{mg} \mathrm{L}^{-1}(99.42$ wt $\%)$. The corresponding quantification of homologic groups under such reaction conditions is summarized in Figure 8.

Referring to Figures 7 and 8 for the chlorination degree of the PCBs, it is evident that the high-chlorinated PCBs were much more easily dechlorinated toward the low homologues when the reaction temperature increased from 280 to $375^{\circ} \mathrm{C}$. This finding indicates that reductive dechlorination in this reaction system occurs stepwise, with the chlorine on the PCBs molecule being sequentially substituted by hydrogen. As the PCBs molecule becomes less chlorinated, the kinetic barrier for



Figure 8. Homologue dependency of transformer oil-contained PCBs degradation on MFA2 ( $2 \mathrm{~g})$ under sub- and supercritical water for 30 min.

dechlorination becomes larger. Eventually when the energy barrier exceeds the energy barrier for ring-opening of biphenyl, destruction of the biphenyl ring generates aliphatic hydrocarbon (butylhexyl-, ethyloctyl-, cyclohexyl-benzene etc) ${ }^{31}$ This postulation is supported by the fact that while some mono-, di-, tri-, and tetrachlorobiphenyls can be identified using GC/MS, virtually biphenyl can be observed from 375 to $410^{\circ} \mathrm{C}$ during $30 \mathrm{~min}$ treatments. Hereby, the proposed PCBs dechlorination pathway on MWI fly ash is depicted in SI Figure S3. In addition, toxic chlorinated hydrocarbons were not observed in GC/MS chromatograms (Figure 7), which implied that they were never directly generated via $\mathrm{C}-\mathrm{C}$ bond cleavage of PCBs before the formation of biphenyl. ${ }^{32}$

Figures 7 and 8 also demonstrate that further increase of reaction temperature led to dechlorination resistance for either low or high chlorinated PCBs. This is because the continuous generation of low chlorinated PCBs and aliphatic hydrocarbons cause the competition with original PCBs in transformer oil for hydrogen sources. It is reported that the resistance of the low homologues toward reductive dechlorination may be related to the increase in the lowest unoccupied molecular orbital (LUMO) energy which decreases the probability of the reductive electron to occupy the LUMO, thus decreasing the probability of the formation of the reactive excimer of the PCBs molecule. ${ }^{33}$ Although dechlorination did not proceed toward completion after $30 \mathrm{~min}$ reaction, it is apparent that the majority of the original PCBs homologues in transformer oil, particularly the high-substituted congeners which are predominant in Aroclor 1260 and typically more toxic, were nearly reduced.

TCLP Experiments. To investigate the leachability of toxic metals from both MWI fly ashes before and after reaction with PCBs, a series of TCLP tests was conducted and the results are displayed in Tables 1 and 2.

The concentrations of $\mathrm{Cu}, \mathrm{Pb}, \mathrm{Zn}$, and $\mathrm{Cd}$ in the leachate of both raw MWI fly ashes greatly surpassed the USEPA and Chinese EPA regulatory limits (except for that of $\mathrm{As}, \mathrm{Ba}$, and $\mathrm{Cr}$ ), implying that both MWI fly ashes are hazardous waste requiring particular control. These results were consistent with those obtained in the sequential extraction tests. The leachability of heavy metals from residues was significantly reduced after supercritical water reaction in the presence of PCBs. The leachability of toxic metals completely meets the permitted limits for landfilling when prolonging the reaction time toward $90 \mathrm{~min}$. Under higher temperature and pressure, 
Table 1. TCLP Results of MFA1 (3 g) Before and After Supercritical Water Reaction at $410{ }^{\circ} \mathrm{C}\left(\mathrm{mg} \mathrm{L}^{-1}\right)$

\begin{tabular}{|c|c|c|c|c|c|c|}
\hline \multirow[b]{2}{*}{ element } & \multirow[b]{2}{*}{ raw MFA1 } & \multicolumn{3}{|c|}{ residues } & \multicolumn{2}{|c|}{ permitted limit } \\
\hline & & $30 \mathrm{~min}$ & $60 \mathrm{~min}$ & $90 \mathrm{~min}$ & USEPA & Chinese EPA \\
\hline As & 1.10 & 0.12 & $\mathrm{nd}^{a}$ & nd & 5 & 5 \\
\hline $\mathrm{Ba}$ & nd & 0.05 & nd & 0.04 & 100 & 100 \\
\hline $\mathrm{Cd}$ & 27.4 & nd & nd & nd & 1 & 1 \\
\hline $\mathrm{Cr}$ & 0.51 & nd & nd & nd & 5 & 5 \\
\hline $\mathrm{Cu}$ & 308.87 & 8.76 & nd & nd & & 100 \\
\hline $\mathrm{Pb}$ & 45.62 & 24.89 & 14.56 & 3.98 & 5 & 5 \\
\hline $\mathrm{Zn}$ & 1083.96 & 11.01 & 2.31 & nd & & 100 \\
\hline$a_{\mathrm{nd}}: \mathrm{n}$ & tected. & & & & & \\
\hline
\end{tabular}

Table 2. TCLP Results of MFA2 (3 g) Before and After Supercritical Water Reaction at $375^{\circ} \mathrm{C}\left(\mathrm{mg} \mathrm{L}^{-1}\right)^{a}$

\begin{tabular}{cccccccc} 
& & \multicolumn{3}{c}{ residues } & & \multicolumn{2}{c}{ permitted limit } \\
\cline { 3 - 5 } \cline { 7 - 8 } element & raw MFA2 & $30 \mathrm{~min}$ & $60 \mathrm{~min}$ & $90 \mathrm{~min}$ & & USEPA & Chinese EPA \\
$\mathrm{As}$ & 0.11 & 0.05 & nd & nd & & 5 & 5 \\
$\mathrm{Ba}$ & 0.04 & 0.04 & 0.03 & 0.03 & & 100 & 100 \\
$\mathrm{Cd}$ & 27.66 & 0.09 & nd & nd & & 1 & 1 \\
$\mathrm{Cr}$ & nd & nd & nd & nd & & 5 & 5 \\
$\mathrm{Cu}$ & 38.04 & 4.76 & 1.12 & nd & & 100 \\
$\mathrm{~Pb}$ & 100.36 & 13.36 & 9.56 & 2.34 & & 5 & 5 \\
$\mathrm{Zn}$ & 1322.68 & 15.02 & 11.24 & 0.13 & & 100
\end{tabular}

$a_{\text {nd: not detected. }}$

acidic gas adsorbed in ash particles releases into the reaction system, and acidic solution could diffuse into interior of ash particles, followed by splitting them into fragments. This behavior contributes greatly to accelerating the leaching rate of toxic metals inside the particle into the liquor. On the other hand, the XRD patterns in SI Figure S1 provided the evidence of new crystals, such as calcium sulfate $\left(\mathrm{CaSO}_{4}\right)$ and ferric oxide $\left(\mathrm{Fe}_{2} \mathrm{O}_{3}\right)$, formed in residues and sodium chloride $(\mathrm{NaCl})$ previously detected in raw ashes are absent after supercritical water reaction. The toxic metals may be either absorbed or physically encapsulated in the stable mineral phases, and hence their mobility can also be prevented by more stable speciation from transferring toward environment. ${ }^{34}$ In addition, it is expected that full destruction of PAHs in both raw MWI fly ashes (SI Table S1) was achieved during supercritical water treatment by GC/MS analysis. After reaction, three new peaks in residues (induced from MFA1) appeared: the peaks centered at $28.48^{\circ}, 47.43^{\circ}$, and $56.26^{\circ}$ can be attributed to cuprous chloride $(\mathrm{CuCl})$ according to the PDF reference files (PDF 010793). Studies on crystal phases of residues revealed that transition metals in MWI fly ashes generated the activity due to the reductive properties of metallic cations.

In summary, both MWI fly ashes show the PCBs degradation potential under sub- and supercritical water. Simultaneously, the residues exhibit an excellent stability of the mineral assemblage and less release of heavy metals relative to raw MWI fly ash. The result from this study indicates that such simultaneous treatment seem to be a very promising alternative for other halogenated contaminants such as brominated flame retardants (BFRs), perfluoroalkylsulfonates, and perfluorocarboxylic. However, these transition metals in MWI fly ashes have the properties of complexity and uncertainty, with close relation to each other, and together they affect the overall dechlorination reaction. Arising from this study, some critical issues such as detailed catalytic mechanism and optimization of destruction efficiency, especially those of the lower chlorinated homologues, are currently being pursued along with initial demonstration of transformer oil-contained PCBs degradation using MWI fly ash. The simultaneous detoxification processes can meet technical and operating-costs requirements for scaleup when compared with strongly reducing metals (noble metals and other metallic catalysts) degradation, electrocatalytic hydrodechlorination, and irradiation, etc., because MWI fly ashes are solid wastes and possess the potential catalysis possibility. On the other hand, supercritical water method may be advantageous for this high-concentration and extremely difficult to treat waste, namely transformer oil-contained PCBs, in terms of energy consumption. Detailed cost analysis and comparison must be performed prior to any recommendation about a practical treatment method.

\section{ASSOCIATED CONTENT}

\section{S Supporting Information}

Supplementary descriptions for the method of PAHs analysis and the sequential extraction procedure, $\mathrm{PAHs}$ concentrations (Table S1), metals composition (Table S2), XRD (Figure S1), SEM (Figure S2), and PCBs dechlorination pathway (Figure S3). This material is available free of charge via the Internet at http://pubs.acs.org.

\section{AUTHOR INFORMATION}

\section{Corresponding Author}

*Phone: +86-10-62849515; fax: +86-10-62849515; e-mail: fszhang@rcees.ac.cn.

\section{Present Address}

${ }^{\ddagger}$ Henan Key Laboratory for Environmental Pollution Control, College of Chemistry and Environmental Sciences, Henan Normal University, 46 East Jianshe Road, Xinxiang 453007, Henan Province, People's Republic of China.

\section{ACKNOWLEDGMENTS}

This work was financially supported by the National Key Technology R\&D Program (2008BAC32B03), China Postdoctoral Science Foundation (20090460543), and National Natural Science Foundation of China (51008296,21077210).

\section{REFERENCES}

(1) Sobiecka, E.; Cedzynska, K.; Bielski, C.; Antizar-Ladislao, B. Biological treatment of transformer oil using commercial mixtures of microorganisms. Int. Biodeter. Biodegr. 2009, 63, 328-333.

(2) Yang, B.; Yu, G.; Huang, J. Electrocatalytic hydrodechlorination of 2,4,5-trichlorobiphenyl on a palladium-modified nickel foam cathode. Environ. Sci. Technol. 2007, 41, 7503-7508.

(3) Yang, B.; Yu, G.; Shuai, D. M. Electrocatalytic hydrodechlorination of 4-chlorobiphenyl in aqueous solution using palladized nickel foam cathode. Chemosphere 2007, 67, 1361-1367.

(4) Yang, B.; Wang, S.; Yu, G.; Zhou, Y. R. Electrocatalytic reduction of 2-chlorobiphenyl in contaminated water using palladium-modified electrode. Sep. Purif. Technol. 2008, 63, 353-359.

(5) Jones, C, G.; Silverman, J.; Al-Sheikhly, M.; Neta, P.; Poster, D, L. Dechlorination of polychlorinated biphenyls in industrial transformer oil by radiolytic and photolytic methods. Environ. Sci. Technol. 2003, $37,5773-5777$.

(6) Mincher, B, J.; Curry, R, C.; Brey, R. Method to simultaneously improve $\mathrm{PCB}$ radiolysis rates in transformer oil and to close the chlorine mass balance. Environ. Sci. Technol. 2000, 34, 3452-3455.

(7) Fan, Y.; Lu, X. B.; Ni, Y. W.; Zhang, H. J.; Zhao, L.; Chen, J. P.; Sun, C. L. Destruction of Polychlorinated Aromatic Compounds by 
Spinel-Type Complex Oxides. Environ. Sci. Technol. 2010, 44, 30793084.

(8) Cho, C. H.; Ihm, S. K. Development of new vanadium-based oxide catalysts for decomposition of chlorinated aromatic pollutants. Environ. Sci. Technol. 2002, 36, 1600-1606.

(9) Zhuang, Y. A ;; Ahn, S.; Luthy, R. G. Debromination of Polybrominated Diphenyl Ethers by Nanoscale Zerovalent Iron: Pathways, Kinetics, and Reactivity. Environ. Sci. Technol. 2010, 44, 8236-8242.

(10) Wei, J. J.; Xu, X. H.; Liu, Y.; Wang, D. H. Catalytic hydrodechlorination of 2,4-dichlorophenol over nanoscale Pd/Fe: Reaction pathway and some experimental parameters. Water Res. 2006, 40, 348-354.

(11) Lin, K. S.; Wang, H. P. Supercritical water oxidation of 2chlorophenol catalyzed by $\mathrm{Cu}^{2+}$ cations and copper oxide clusters. Environ. Sci. Technol. 2000, 34, 4849-4854.

(12) Marulanda, V.; Bolanos, G. Supercritical water oxidation of a heavily PCB-contaminated mineral transformer oil: Laboratory-scale data and economic assessment. J. Supercrit. Fluid 2010, 54, 258-265.

(13) Kubátová, A.; Herman, J.; Steckler, T. S.; De Veij, M.; Miller, D. J.; Klunder, E. B.; Wal, C. M.; Hawthorne, S. B. Subcritical (hot/ liquid) water dechlorination of PCBs (Aroclor 1254) with metal additives and in waste paint. Environ. Sci. Technol. 2003, 37, 57575762.

(14) Hori, H.; Nagaoka, Y.; Yamamoto, A.; Sano, T.; Yamashita, N.; Taniyasu, S.; Kutsuna, S.; Osaka, I.; Arakawa, R. Efficient decomposition of environmentally persistent perfluorooctanesulfonate and related fluorochemicals using zerovalent iron in subcritical water. Environ. Sci. Technol. 2006, 40, 1049-1054.

(15) Yak, H. K.; Lang, Q. Y.; Wai, C. M. Relative resistance of positional isomers of polychlorinated biphenyls toward reductive dechlorination by zerovalent iron in subcritical water. Environ. Sci. Technol. 2000, 34, 2792-2798.

(16) Zhu, N. M.; Li, Y.; Zhang, F. S. Catalytic dechlorination of polychlorinated biphenyls in subcritical water by $\mathrm{Ni} / \mathrm{Fe}$ nanoparticles. Chem. Eng. J. 2011, 171, 919-925.

(17) Jin, J. A.; Li, X. D.; Chi, Y.; Yan, J. H. Heavy metals stabilization in medical waste incinerator fly ash using alkaline assisted supercritical water technology. Waste Manage. Res. 2010, 28, 1133-1142.

(18) Bo, D.; Zhang, F. S.; Zhao, L. J. Influence of supercritical water treatment on heavy metals in medical waste incinerator fly ash. $J$. Hazard. Mater. 2009, 170, 66-71.

(19) Sako, T.; Sugeta, T.; Otake, K.; Sato, M.; Tsugumi, M.; Hiaki, T.; Hongo, M. J. Decomposition of dioxins in fly ash with supercritical water oxidation. Chem. Eng. Jpn. 1997, 30, 744-747.

(20) Erickson, M. D. Analytical Chemistry of PCBs, 2nd ed.; CRC: New York, 1997.

(21) Berset, J. D.; Ejem, M.; Holzer, R.; Lischer, P. Comparison of different drying, extraction and detection techniques for the determination of priority aromatic hydrocarbons in background contaminated soil samples. Anal. Chim. Acta 1999, 383, 263-275.

(22) Frame, G. M.; Wagner, R. E.; Carnahan, J. C.; Brown, J. F. Jr.; May, R. J.; Smullen, L. A.; Bedard, D. L. Comprehensive, quantitative, congener-specific analyses of eight aroclors and complete $\mathrm{PCB}$ congener assignments on DB-1 capillary GC columns. Chemosphere 1996, 33, 603-623.

(23) Tessier, A.; Campbell, P. G. C.; Bisson, M. Sequential extraction procedure for the speciation of particulate trace metals. Anal. Chem. 1979, 51, 844-851.

(24) William, P.; Linak, Wendt; Jost, O. L. Toxic metal emissions from incineration: Mechanisms and control. Prog. Energy Combust. 1993, 19, 145-185.

(25) Chou, J. D.; Wey, M. Y.; Chang, S. H. Evaluation of the distribution patterns of $\mathrm{Pb}, \mathrm{Cu}$ and $\mathrm{Cd}$ from MSWI fly ash during thermal treatment by sequential extraction procedure. J. Hazard. Mater. 2009, 162, 1000-1006.

(26) Zhang, Y. M.; Sun, W.; Yan, H. D. Hydration of high-volume fly ash cement pastes. Cement Concrete Comp. 2000, 22, 445-452.
(27) Zhao, L. j.; Zhang, F. S.; Wang, K. S.; Zhu, J. X. Chemical properties of heavy metals in typical hospital waste incinerator ashes in China. Waste Manage. 2008, 29, 1114-1121.

(28) Hatanaka, T.; Kitajima, A.; Takeuchi, M. Role of copper chloride in the formation of polychlorinated dibenzo-p-dioxins and dibenzofurans during incineration. Chemosphere 2004, 57, 73-79.

(29) Tan, L. C.; Choa, V.; Tay, J. H. The influence of pH on mobility of heavy metals from municipal solid waste incinerator fly ash. Environ. Monit. Assess. 1997, 44, 275-284.

(30) Lewin, A. H.; Cohen, T. Mechanism of Ullmann reactiondetection of an organocopper intermediate. Tetrahedron Lett. 1965, $4531-4536$

(31) Yak, H. K.; Wenclawiak, B. W.; Cheng, I. F.; Doyle, J. G.; Wai, C. M. Reductive dechlorination of polychlorinated biphenyls by zerovalent iron in subcritical water. Environ. Sci. Technol. 1999, 33, $1307-1310$

(32) Öztürk, İ.; Irmak, S.; Hesenov, A.; Erbatur, O. Hydrolysis of kenaf (Hibiscus cannabinus L.) stems by catalytical thermal treatment in subcritical water. Biomass Bioenergy 2010, 34, 1578-1585.

(33) Arbon, R. E.; Mincher, B. J.; Knighton, W. B. $\gamma$-Ray destruction of individual $\mathrm{PCB}$ congeners in neutral 2-propanol. Environ. Sci. Technol. 1994, 28, 2191-2196.

(34) Jin, J.; Li, X. D.; Chi, Y.; Yan, J. H. Co-disposal of heavy metals containing waste water and medical waste incinerator fly ash by hydrothermal process with addition of sodium carbonate: A case study on $\mathrm{Cu}(\mathrm{II})$ removal. Water, Air Soil Pollut. 2010, 209, 391-400. 